\title{
Função socioambiental do contrato: mecanismo de compatibilidade entre o crescimento econômico e o meio ambiente
}

\author{
ENVIRONMENTAL FUNCTION OF CONTRACT: \\ MECHANISM OF COMPATIBILITY BETWEEN \\ ECONOMIC GROWTH AND THE ENVIRONMENT
}

\author{
Miguel Etinger de Araujo Junior* \\ Karina Alves Teixeira**
}

Resumo: Este artigo tem por objetivo demonstrar como a função social do contrato pode servir como mecanismo de tutela ao meio ambiente. Para tanto, é iniciado com uma breve abordagem sobre economia, direito e Estado. Na sequência aborda-se o aspecto constitucional da compatibilidade do desenvolvimento econômico com o direito ao meio ambiente ecologicamente equilibrado. Logo adiante explana-se acerca do contrato e de sua função social. Por fim, aborda-se os diversos aspectos da função socioambiental do contrato, destacando as formas para sua operacionalização pelo Poder Judiciário e pelo Ministério Público, bem como as consequências de seu descumprimento. Ao fim, conclui-se que a função socioambiental do contrato trata-se de um mecanismo de compatibilidade entre o crescimento econômico e o meio ambiente.

Palavras-chave: Economia; Estado ambiental; Contrato; Função social; Função socioambiental.

Abstract: This article aims to demonstrate how the social function of the contract can serve as a mechanism for safeguarding the environment. To do so, starts with a brief discussion about economics, law and the state. Following addresses the constitutional aspect of the compatibility of economic development with the right to an ecologically balanced environment. Once below explains about the contract itself and its social function. Finally, one addresses the various aspects of the environmental function of the contract, highlighting the ways for its operationalization by the judiciary and the Public Ministry, as well as the consequences of noncompliance. At the end, it is concluded that the function of environmental contract involves a mechanism compatibility between economic growth and the environment.

Keywords: Economics; Environmental status; Contract; Social function; Environmental function. 


\section{INTRODUÇÃO}

O desenfreado crescimento econômico fomentado pelo capitalismo galgou sérios problemas de ordem ambiental, emergindo desta crise a construção do Estado Ambiental, unindo ente estatal e sociedade na defesa do meio ambiente, com o escopo de consolidação do desenvolvimento sustentável, onde deve haver incentivo à evolução do mercado, ato contínuo ao controle e tutela dos recursos naturais, vislumbrando a garantia de uma existência digna a todos os seres humanos.

Em observância às grandes fontes movimentadoras de lucro, foi constatado ser o contrato um dos maiores vetores movimentadores da economia, assim, o Estado, através do Direito, introduziu legalmente neste instrumento a exigência do cumprimento de uma função social, impondo que na celebração de pactos negociais deve-se promover tanto a satisfação dos envolvidos como os interesses da sociedade, o que se aplica inclusive aos contratos que envolvem questões ambientais, com o escopo de garantir o direito de todos a um meio ambiente preservado para as presentes e futuras gerações, o que foi denominado de função socioambiental do contrato

Estabelecida legalmente a obrigatoriedade de cumprimento a função social e socioambiental do contrato, hodiernamente algumas das grandes discussão que giram em torno da problemática dos mecanismos de operacionalização destes institutos, bem como as consequências de seu descumprimento, o que se discutirá neste breve estudo.

\section{NOTAS SOBRE A RELAÇÃO ENTRE ECONOMIA, DIREITO E ESTADO}

Há aproximadamente três séculos o mundo transita imerso num sistema capitalista, onde se intui a todo e qualquer custo a obtenção de lucro, que se sustenta sob dois pilares principais: a propriedade privada dos meios de produção e os contratos.

Assim sendo, a economia é movimentada, regulada e controlada pelo funcionamento do mercado, que é gerenciado primordialmente pelas pessoas jurídicas, o que exige a manutenção de uma estrutura política e econômica sob as quais se funde, onde ao mesmo tempo em que o crescimento é extremamente importante para a organização da sociedade comercial, a 
economia se incorpora às relações sociais ao invés de se congregar ao sistema econômico (POLANYI, 1992).

Em razão desta situação, torna-se indispensável a imposição de um determinado regramento, ou seja, de uma atuação estatal, que costumeiramente ocorre através do Direito, sob pena da autodestruição deste mercado econômico por intermédio de monopólios, oligopólios, acordo para a formação de dumpings, cartéis, etc.

O Direito traz em seu foco a relação humana, e como bem salienta Miguel Reale (2002, p. 2), "corresponde à exigência essencial e indeclinável de uma convivência ordenada, pois nenhuma sociedade poderia subsistir sem um mínimo de ordem", possuindo o desígnio de regular as ações humanas indispensáveis à convivência harmônica dentro da coletividade.

Em contrapartida, a Economia trata-se de uma ciência explicativa, tendo como escopo explicitar os fenômenos econômicos, não determinando comportamento aos indivíduos.

Contudo, considerando que o fato econômico se consolida na coletividade como um fato social relevante, demonstra-se suscetível à intervenção do Direito, percebendo-se a partir de então a importância da Economia que interfere nas relações sociais e, portanto, no Direito, haja vista que explica o ato e o fato disciplinado no ordenamento jurídico.

A sociedade trouxe ao Direito a necessidade de atuação conjunta com a Economia, de modo a propiciar que não somente o lucro seja vislumbrado nas relações sociais e jurídicas, mas também todo um conjunto de valores relevantes ao indivíduo e à coletividade em que se insere, pautando-se em princípios de civilidade e mútuo respeito, sendo que o contrário representaria a escravização social mediante o abuso do poder econômico.

Sob esta conjuntura, as Constituições democráticas, inclusive a Carta Política brasileira, estão à espera de uma interpretação que lhes proporcionem a solidificação de todos os valores humanos e econômicos que devem nortear a sociedade e as relações humanas.

Sérgio Alves Gomes (2008, p. 201) bem alerta que o estudo das relações entre Direito e Economia pode revelar que a última deve ocupar seu espaço no mercado, todavia se o escopo for a edificação de uma sociedade bem ordenada, fundamentada em princípios de justiça, há que se impedir que o poder econômico invada as demais esferas do mundo cultural, 
especialmente o campo do Direito, extirpando as possibilidades de ataques a distintos valores igualmente fundamentais ao homem.

É necessário vislumbrar que tanto o Direito quanto a Economia foram criados para servirem e auxiliarem todos os seres humanos e não apenas uma parcela destes, desta feita, realizando o poder econômico a coisificação do ser humano, no sentido kantiano, imperativamente o Estado Democrático de Direito deve intervir regulando estas relações econômicas.

Contemporaneamente o Direito deve manter-se em linhas opostas à ganância do mercado de modo a garantir a dignidade da pessoa humana.

\section{O ASPECTO CONSTITUCIONAL DA COMPATIBILIDADE DO CRESCIMENTO DA ATIVIDADE ECONÔMICA COM O DIREITO AO MEIO AMBIENTE ECOLOGICAMENTE EQUILIBRADO}

O Estado como agente econômico não corresponde à negatória do capitalismo, mas responde à necessidade de sua lógica interna de expansão, sendo indispensável para o funcionamento do mercado, se apresentando como um meio decisivo para sua estabilidade.

Durante um longo interregno buscou-se exclusivamente a estabilidade do mercado capitalista desencadeando um irresponsável crescimento econômico, todavia o alargamento financeiro despendeu um custo bastante alto em detrimento do meio ambiente, olvidou-se que a economia é também indissociável da natureza, haja vista ser esta sua grande fonte de recursos, o que desencadeou um verdadeiro colapso ambiental.

Ante a crise dos recursos naturais, iniciou-se a construção do Estado Ambiental, que é muito bem conceituado por Canotilho (1999, p. 32):

A qualificação de um Estado como "Estado Ambiental" aponta para duas dimensões jurídico-políticas particularmente relevantes. A primeira é a obrigação de o Estado, em cooperação com outros Estados e cidadãos ou grupos da sociedade civil, promover políticas públicas (econômicas, educativas, de ordenamento) pautadas pelas exigências da sustentabilidade ecológica. A segunda relaciona-se com o dever de adopção de comportamentos públicos e privados amigos do ambiente de forma a dar expressão concreta à assumpção da responsabilidade dos poderes públicos perante as gerações futuras. 
De forma mais sintética, Michael Kloepfer (2010, p. 43) explica no que consiste este novo Estado:

O Estado ambiental refere-se a um Estado que faz da incolumidade do seu meio ambiente sua tarefa, bem como o critério e a meta procedimental de suas decisões. Isto, porém, não significa que o âmbito social, ou seja, não estatal deva ser excluído da investigação.

Assim, o surgimento do Estado Ambiental enseja a necessidade de alterações nas Constituições dos países que o adotam.

O Brasil já demonstrou seu intervencionismo no âmbito ambiental com a elaboração da Constituição Federal de 1988 que prima pelo meio ambiente, inserindo o Estado Democrático de Direito brasileiro nos moldes de um Estado Ambiental, pautado na participação política bifurcada entre Estado e comunidade, criando uma inter-relação entre o aparato estatal e as ações dos indivíduos para a realização das normas constitucionais.

$\mathrm{Na}$ esteira do Estado Ambiental onde Estado e sociedade atuam conjuntamente, a Constituição da República Federativa do Brasil dispõe em seu texto:

"Art. 225. Todos têm direito a um meio ambiente ecologicamente equilibrado, bem de uso comum do povo e essencial à sadia qualidade de vida, impondo-se ao Poder Público e a coletividade o dever de defendêlo e preservá-lo para as presentes e futuras gerações."

O Estado Ambiental surge para a consolidação da igualdade entre a sua população, incentivando o desenvolvimento econômico ato contínuo ao controle dos recursos naturais, incumbindo ao Poder Público e à sociedade a tutela do meio ambiente, de forma que os recursos disponíveis contemporaneamente estejam também à disposição das futuras gerações.

Em paridade de relevância, a ordem econômica também ganhou destaque junto ao texto constitucional de 1988, que se inclinou para a sua estabilização, autorizando, inclusive, o desenvolvimento de atividades econômicas pelo Estado em conjunto com agentes privados, visando consolidar as bases para o desenvolvimento econômico.

Para Habermas (1973, p. 55) a atuação do Estado junto à esfera econômica também é dupla, operando, ora substitutivamente, ora 
compensatoriamente. As atuações substitutivas podem ser demonstradas como as ações juridicamente elaboradas com o escopo de atingir os fatos econômicos de modo a impulsionar um sistema econômico deficiente. Já nas atuações compensatórias o Estado almeja adequar as consequências disfuncionais que o processo de acumulação produz, como no caso das externalizações dos custos de mercado.

Esta atuação do Estado na esfera econômica se dá majoritariamente através do Direito, que como bem destaca Nobert Reich (1985, p. 78) possui uma dupla instrumentalidade, haja vista que se apresenta como um mecanismo apto ao cumprimento de objetivos previstos pelos operadores do mercado, bem como um instrumento direcionador a serviço do Estado.

O Direito como aparato da ação do Estado atua por intermédio de normas organizadoras e autorizadoras, delimitando o direcionamento global da economia, agindo ainda de maneira conjuntural com normas interventivas atuantes direta ou indiretamente.

O direcionamento da ordem econômica na seara brasileira é bem delineado pela Constituição Federal que prevê:

“Art. 170. A ordem econômica, fundada na valorização do trabalho humano e na livre iniciativa, tem por fim assegurar a todos existência digna, conforme os ditames da justiça social, observados os seguintes princípios: I - soberania nacional; II - propriedade privada; III - função social da propriedade; IV - livre concorrência; V - defesa do consumidor; VI defesa do meio ambiente, inclusive mediante tratamento diferenciado conforme o impacto ambiental dos produtos e serviços e de seus processos de elaboração e prestação; VII - redução das desigualdades regionais e sociais; VIII - busca do pleno emprego; IX - tratamento favorecido para as empresas de pequeno porte constituídas sob as leis brasileiras e que tenham sua sede e administração no País. Parágrafo único. É assegurado a todos o livre exercício de qualquer atividade econômica, independentemente de autorização de órgão públicos, salvo nos casos previstos em lei."

O que se depreende do texto constitucional é que a ordem econômica possui o escopo de assegurar a todos uma existência digna, pautando-se na justiça social, devendo observar, obrigatoriamente, princípios como o da soberania nacional, da função social da propriedade, da livre concorrência, 
da defesa do meio ambiente dentre outros, sendo estes princípios base para a composição do princípio-essência ${ }^{1}$ da dignidade da pessoa humana.

$\mathrm{Na}$ atividade econômica o princípio mais sobressalente é o da livre iniciativa, que consiste numa das bases estruturais do capitalismo, se apresentando como um ideal de liberdade econômica, almejando assegurar aos indivíduos a livre escolha da atividade que desejam desempenhar para seu sustento, limitando a atuação estatal na esfera das opções econômicas dos agentes, todavia, a livre iniciativa não representa uma imunidade a qualquer tipo de regulação estatal, haja vista que a função social da propriedade e a justiça social obstam o exercício irrestrito da liberdade de conteúdo econômico.

Não reside a livre iniciativa na ampla outorga de liberdade para o exercício de atividades econômicas, estas podem ser livremente desempenhadas desde que não atinjam negativamente o bem comum, estando incluído neste o direito a um meio ambiente ecologicamente equilibrado.

Por evidente que o ente estatal deve estimular a atividade econômica através de políticas públicas, haja vista ser esta a responsável pela sobrevivência do Estado Social - que hodiernamente deve se adequar ao Estado Ambiental -, pois a queda da produtividade reflete negativamente na economia do Estado.

A situação é bastante delicada, a queda da produtividade de um Estado que acarreta a debilidade da economia não depende exclusivamente de incentivos ou reguladores financeiros, mas fica a mercê também da existência de recursos naturais suficientes para a continuidade e quiçá o aumento da produção industrial.

O papel do Estado junto ao meio ambiente e à ordem econômica é a conciliação destes dois fatores de extrema relevância para a coletividade de modo a garantir a mantença do bem comum, oferecendo aparato suficiente para ao desenvolvimento econômico ato contínuo à promoção da tutela ambiental, consolidando o tão desejado desenvolvimento sustentável, que se refere "a qualidade daqueles que é sustentável, passando a incorporar o significado de manutenção e conservação ab eterno dos recursos naturais"

\footnotetext{
Terminologia adotada por Cristiane Derani (2008, p. 22) para denominar duas representações de valores presentes na Constituição Federal: os princípios conformadores, que são princípios fundamentais que orientam todas as interpretações das normas constitucionais e demais produções normativas; e os princípios impositivos, que estão subsumidos a todos os demais princípios que se impõe aos órgãos do Estado, traçando diretrizes da sua atividade política e administrativa.
} 
(BARBIERI, 2009), que representa a melhoria da qualidade de vida humana dentro dos limites de suporte da capacidade do planeta.

A constatação do inter-relacionamento entre meio ambiente e a ordem econômica aparenta certa obviedade, haja vista que o ordenamento jurídico sempre deve ser interpretado de maneira sistemática e não isoladamente, sendo notório "que os elementos que compõem a norma expressa no art. 225 estão na realidade interagindo com os elementos tratados pela norma do art. 170" (DERANI, 2008), ou seja, todos os aspectos que envolvem a ordem econômica afetarão o meio ambiente, assim como os que afetarem a natureza refletirão na ordem econômica.

Não se pode mais conceber o desenvolvimento de uma atividade econômica sem a utilização racional dos recursos naturais, a fim de garantir a todos uma existência digna pautada nas justiças sociais, sendo mister ainda analisar o aspecto contratual da questão, haja vista ser este um dos principais instrumentos potencializadores do desenvolvimento econômico.

\section{O CONTRATO E SUA FUNÇÃO SOCIAL}

Trata-se o contrato de espécie de notável relevância social e econômica do negócio jurídico e assim, instrumento por excelência de circulação de riquezas, como justa medida de interesses contrapostos, sendo, indubitavelmente, esteio socioeconômico do mundo.

Neste diapasão, vale ressaltar as palavras de Stolze Gagliano e Pamplona Filho (2011, p. 38) que afirmam "que o matiz ideológico do contrato é pintado segundo a época e a conjuntura social em que ele é celebrado", ou seja, o contrato se adapta às necessidades econômicas e principalmente sociais, privilegiando, contemporaneamente o útil, o justo e sua função social.

Para Cláudio Godoy (2004, p. 111), inexiste atualmente um conceito autônomo de função social, inclusive a do contrato, havendo em verdade um movimento de funcionalização do direito e dos institutos jurídicos.

Esta funcionalização dos institutos jurídicos obriga-os ao abandono do objetivo egoístico da solução de conflito entre as partes, passando a adotar uma nova atribuição, voltada à organização social, mormente nas relações que envolvem direito e economia, se revelando nas situações em que o exercício do poderes outorgados ao indivíduo, dentre estes, o da autonomia privada, se efetiva como forma de afirmação da pessoa e de sua 
dignidade, desde que essa consecução manifeste igualmente alguma utilidade social (AMARAL, 1999/2000, p. 380).

Contudo, não significa que a função social do contrato se sobrepõe aos princípios contratuais clássicos como a autonomia privada, intangibilidade do conteúdo do contrato e relatividade de seus efeitos, dentre outros, mas sim os complementam (MORAES, 2006, prefácio).

A função social do contrato provoca importante oxigenação no instituto do contrato ao apresentar elementos que buscam concretizar as diretrizes constitucionais de respeito aos interesses existenciais das pessoas e de promoção de um contrato socialmente justo, atuando na promoção de um modelo de pacto adequado aos ditames constitucionais.

A função social do contrato advém do posicionamento estatal intervencionista nas relações privadas, no intuito de abandonar o escopo pactual único de satisfação dos contraentes e instaurar o objetivo social de proteção aos interesses da coletividade inevitavelmente atingidos nas convenções, uma vez que o instituto contratual não pode ser considerado de forma isolada, ao passo que interfere negativa e positivamente em bens titularizados não apenas por determinados indivíduos, mas sim pela sociedade.

Ato contínuo, o cenário mundial ambiental reivindica sustentabilidade, equilíbrio no manejo e utilização de recursos naturais e por sua vez, o contrato pode ser considerado como um dos mecanismos de maior influência no desenvolvimento de operações econômicas. Desta forma, visando possibilitar a concretização do desenvolvimento sustentável é que se ramificou a função social do contrato, emergindo a função socioambiental do contrato.

\section{OS DIVERSOS ASPECTOS DA FUNÇÃO SOCIOAMBIENTAL DO CONTRATO}

A função socioambiental do contrato abrange inúmeros aspectos como sua aplicabilidade, as conseqüências de seu descumprimento e sua operacionalização junto ao Estado e a cidadania, sendo importante que cada uma destas esferas sejam abordadas especificamente.

\subsection{A Função Socioambiental do Contrato}

Com a introdução da função social nos contratos, o pacto, além de promover a satisfação das partes que o celebram deve atender também ao 
interesses sociais e quando este fator não for possível, deve ao menos se abster de produzir reflexos negativos junto à sociedade, inclusive em seu meio ambiente, o que se denomina de atendimento à função socioambiental do contrato, que deve ser analisada sob o aspecto intrínseco e extrínseco.

Internamente deve o acordo manter prestação e contraprestação equacionadas em harmonia, não podendo servir para apenas uma das partes, isto é, deve haver atendimento ao princípio do equilíbrio econômico do pacto que encontra fundamento jurídico no art. $3^{\circ}$., inciso III da Constituição Federal, consistindo em uma das exigências dos objetivos fundamentais da República Federativa do Brasil, onde se consagra o princípio da igualdade substancial.

Neste sentido, salienta Teresa Negreiros (2006, p. 45) que "o contrato não deve servir de instrumento para que, sob a capa de um equilíbrio meramente formal, as prestações em favor de um contratante lhe acarretem um lucro exagerado em detrimento de outro contratante".

$\mathrm{O}$ equilíbrio contratual pode ser expressado pelo que se mostra razoável às partes celebrantes, considerando que ambas possuem interesses dependentes e necessitam de uma atuação recíproca e colaborativa, motivo pelo qual optaram pela celebração do pacto.

No que tange ao equilíbrio contratual se manifesta Roxana Borges (2008, p. 11):

"Não é possível, na ordem jurídica atual, admitir-se que alguém se proponha a compor uma relação contratual e atue contrariamente à consecução dos fins daquele vínculo, assim como não se admite que um contrato bilateral e oneroso produza vantagens para apenas uma das partes, deixando a outra em situação de frustração e prejuízo."

Toma-se como exemplo um contrato de compra e venda de agrotóxicos celebrado entre a empresa produtora e o agricultor, este instrumento deve sob a égide interna, necessariamente satisfazer o interesse de lucro da produtora, bem como atender as expectativas do produtor junto ao controle de pragas, tudo se dando dentro dos limites da equidade e da boa-fé objetiva, controlando a conduta das partes durante todo o desenvolvimento da avença contratual e até mesmo posteriormente nos casos em que esta conduta de colaboração pode ser considerada como a esperada dentro de uma sociedade justa. 
Sob outra ótica, o acordo também deve atender ao seu aspecto externo, onde se vincula aos efeitos produzidos junto à sociedade, ou seja, veda-se que um pacto, mesmo que celebrado dentro de suas condições de validade (agente capaz, contendo objeto lícito e forma prescrita ou não defesa em lei), venha projetar seus reflexos negativos em pessoas que sequer participaram da relação contratual, inclusive na seara ambiental.

Desta feita, num contrato de construção, por exemplo, onde o empreiteiro se comprometa com o outro pactuante na construção de uma casa com estrutura em madeira, que não seja devidamente certificada, embora esteja sendo cumprido o aspecto interno no pacto, a função social deste aspecto externo - não está sendo atendida ao passo que o desmatamento ilegal provoca impactos negativos em toda a coletividade.

Atendida a função social socioambiental do contrato, além das partes diretamente envolvidas no pacto, ganha também a sociedade enquanto titular do direto difuso a um meio ambiente ecologicamente equilibrado, coletividade esta que tem, juntamente com o Estado, o ônus da tutela ambiental, devendo garantir que os recursos naturais estejam disponíveis para as presentes e futuras gerações.

Em razão da relevância do meio ambiente para a sociedade, a função socioambiental do contrato foi elevada a um dos mais altos graus de essência do Estado Democrático de Direito, motivo pelo qual os particulares não podem deixar de observá-lo, possibilitando a terceiros que se oponham a pactos prejudiciais a natureza, seja pela via administrativa, seja pela via judicial (BARROSO, 2005, p. 34).

A função socioambiental do contrato impõe a defesa e proteção do meio ambiente quando da celebração de pactos, o que demonstra não apenas uma evolução jurídica, mas também um progresso social no que tange à busca da melhoria da qualidade de vida dos seres vivos no planeta.

\subsection{A Operacionalização da Função Socioambiental do Contrato pelo Poder Judiciário e pelo Ministério Público}

Hodiernamente com o estágio de desenvolvimento dos Estados e da sociedade, qualquer concepção que admita a utilização do instrumento contratual, seja ele público ou privado, em oposição aos interesses da coletividade, de forma que as vantagens auferidas na esfera particular ou administrativa atuem em desfavor do equilíbrio ambiental é condenável. 
Mesmo que um contrato traga muitos benefícios para as partes contratantes, não há viabilidade para sua homologação junto ao Poder Judiciário caso traga prejuízos, mesmo que indiretamente ao meio ambiente e consequentemente à sociedade.

A tutela de fatores ambientais encontram ampla previsão legal, sendo eleitos como normas de ordem pública, não sendo facultado às partes contratantes derrogá-las. Tais fatores ambientais possibilitam ainda a oposição de terceiros às convenções que tenham por objeto questão prejudicial ao meio ambiente, seja ela jurídica ou ambiental, o que se dará pela atuação administrativa (através do Estado) ou judicial (por intermédio de particulares, seus substitutos processuais ou pelo próprio Estado) (BARROSO, 2008, p. 47).

Os principais responsáveis fáticos pela operacionalização da tutela ambiental são o Poder Judiciário e o Ministério Público.

É por intermédio do Poder Judiciário que os direitos da cidadania poderão ser exercidos, haja vista que nenhuma ameaça ou lesão a direito pode ser subtraída de sua apreciação, como bem garante o artigo $5^{\circ}$., inciso XXXV da Constituição Federal.

Todas as questões levadas à apreciação do Poder Judiciário são relevantes e exigem máxima atenção e dedicação do magistrado, contudo, as demandas que envolvem questões ambientais apresentam-se ainda mais complexas, afinal, discutem situações que podem provocar danos irreparáveis junto ao meio ambiente.

Édis Milaré (2013, p. 1.323) bem sintetiza a complexidade das questões ambientais e a problemática em que são inseridos os magistrados:

Na tutela jurisdicional do meio ambiente, pode o juiz defrontar-se com duas posições geralmente antagônicas, que não atendem à necessidade social de desenvolvimento sustentável. De um lado, a defesa cega de determinados bens ambientais, numa visão reducionista e eivada de insensibilidade ante o imperativo de avanços econômicos e sociais. De outro, as falácias que mascaram a inviabilidade ecológica de empreendimentos, este sim insensíveis à preservação da qualidade ambiental e dos recursos naturais necessários às presentes e futuras gerações.

Teoricamente, a imparcialidade do magistrado deve prevalecer, principalmente nas decisões conflitantes acerca de um mesmo objeto, 
variando o grau de dificuldade de acordo com a complexidade de seu objeto e as circunstâncias de cada caso concreto e é justamente pela abstrusão do objeto nas causa ambientais que o papel do Poder Judiciário se torna cada vez mais delicado.

Ademais, os direitos transindividuais reclamam, em sua grande maioria, uma tutela de urgência, que objetiva em verdade não a reparação do dano, até mesmo porque se consumado são de difícil ou impossível reparação, mas sim a sua ocorrência.

Muitos são os interesses a conciliar, principalmente quando a degradação/poluição ambiental está se consolidando por intermédio de uma relação obrigacional, envolvendo propriedade, livre iniciativa, o meio ambiente e a qualidade de vida da coletividade, incumbindo assim ao Poder Judiciário justamente a conciliação da qualidade ambiental com a boa gestão dos recursos naturais, no que consiste o imperativo do desenvolvimento sustentável, o que evidentemente só pode ser solucionado por uma visão multidisciplinar e abrangente do magistrado, operacionalizando a função socioambiental do contrato.

Numa seara tão delicada quanto a ambiental, o Poder Judiciário por intermédio do magistrado deve proferir decisão mais acertada e justa possível, revestindo-se sempre de caráter pedagógico, promovendo verdadeira conscientização a respeito da necessidade de preservação ambiental.

Além disso, nos casos que envolvem relações contratuais, obrigatoriamente devem operar a cláusula geral da função social do contrato de modo a garantir a tutela ambiental e na medida do possível conservar o negócio jurídico, afinal o desenvolvimento econômico também não pode ser desprezado, sendo imprescindível a conciliação entre estes de maneira a formar o desenvolvimento sustentável.

Sob outro enfoque o Ministério Público também promove a operacionalização da função socioambiental dos contratos.

De acordo com o artigo 127 da Constituição Federal, “o Ministério Público é instituição permanente, essencial à função jurisdicional do Estado, incumbindo-lhe a defesa da ordem jurídica, do regime democrático e dos interesses sociais e individuais indisponíveis", assim, a instituição é voltada à representação judicial dos interesses sociais, lhe sendo incumbência constitucional a defesa do meio ambiente.

Embora seja dever de todos zelar pela tutela ambiental, em casos de extrema gravidade, apenas a atuação do Ministério Público se apresenta 
aficaz a compelir, seja particulares, seja o Poder Público, à adoção de soluções de caráter definitivo e muitos destes casos são desencadeados pela realização de contratos que descumprem com sua função sociambiental, incumbindo ao Órgão Ministerial sua operacionalização.

Por evidente que há instrumentos jurídicos que podem ser manejados pelo Ministério Público e outros legitimados, que apresentam-se como aptos a garantirem a proteção aos recursos naturais em conjunto com a função social ambiental do contrato ou isoladamente, podendo e devendo serem utilizados quando a ameaça ao meio ambiente ou o dano ambiental decorrerem da relação contratual, possuindo sempre o escopo de impedimento do dano e quando isso não for possível, a recuperação deste, onde o Estado obriga os agentes poluidores a repararem as lesões perpetradas em desfavor do meio ambiente e suportados pela sociedade.

Assim, considerando o caráter difuso e transindividual do meio ambiente, o ordenamento jurídico estabeleceu alguns mecanismos extrajudiciais, como o inquérito civil e o termo de ajustamento de conduta onde o Ministério Público pode ter atuação bastante eficaz mediante a utilização de poderes investigatórios e requisitórios de que está imbuído - e alguns judiciais, dentre estes o mandado de segurança coletivo, a ação popular constitucional, a ação civil pública e o mandado de injunção, sempre visando a tutela ambiental.

\subsection{As Consequências do Descumprimento da Função Socioambiental do Contrato}

Nas últimas décadas, embora se tenha promovido um grande alargamento de ações nacionais e internacionais com o intuito de proteção ambiental, há ainda muito a se fazer, principalmente no que tange aos processos produtivos, onde ainda prevalece a prática do maior lucro com o menor dispêndio de investimento, gerando progressivamente preocupação com o meio ambiente e a finitude de recursos naturais.

Sob o aspecto contratual constata-se a contínua inobservância das diretrizes ambientais, o que acaba por macular a função socioambiental dos pactos negociais, não havendo ainda uma uniformidade doutrinária no que tange às implicações deste descumprimento, que variam entre inexistência, nulidade, ineficácia e o dever de indenização. 
Em análise isolada ao artigo 421 do Código Civil não se conclui a consequência jurídica da infração à função social e socioambiental do contrato, havendo uma forte tendência à análise do dispositivo em conjunto com o parágrafo único do artigo 2.035, do mesmo Codex, que prevê que "nenhuma convenção prevalecerá se contrariar preceitos de ordem pública, tais como os estabelecidos por este Código para assegurar a função social da propriedade e dos contratos".

Contudo, o dispositivo legal invocado igualmente não revela se a ausência de prevalência atacará os planos da existência, da validade ou da eficácia contratual.

Adotando um posicionamento bastante eclético, Nelson Nery Júnior e Rosa Maria de Andrade Nery (2003, p. 78) sustentam que a função social do contrato pode ensejar soluções distintas de acordo com cada caso concreto:

“Como a função social é cláusula geral, o juiz poderá preencher os claros do que significa essa função social, com valores jurídicos, sociais, econômicos e morais. A solução será dada diante do que se apresentar, no caso concreto, ao juiz. Poderá proclamar a inexistência do contrato pro falta de objeto; declarar sua nulidade por fraude à lei imperativa $(\mathrm{CC}$, 166, VI), porque a norma do CC 421 é de ordem pública (CC 2035 par. ún.); convalidar o contrato anulável (CC 171 e 172); determinar a indenização da parte que desatendeu a função social do contrato etc. São múltiplas as possibilidades que se oferecem como soluções ao problema do desatendimento à cláusula geral da função social do contrato."

Flávio Tartuce (2007, p. 110) se posiciona no sentido de que o descumprimento da função social do contrato provoca lesão no plano de validade ou no de eficácia do contrato, o que variará conforme o caso concreto.

Destoando do linear acima, Paulo Nalin (2010, p. 62) asserta que celebrado o negócio jurídico através de um contrato é evidentemente a existência de efeitos jurídicos, pelo que não se pode falar em inexistência contratual, entretanto, se os efeitos que este pacto gera às partes ou à sociedade são negativos é nítido que o elemento a ser atingido é o da invalidade jurídica, que ocorrerá por intermédio da nulidade ou da anulabilidade, devendo prevalecer a primeira, em razão do grau de relevância 
da função social do contrato, sendo esta considerada norma de ordem pública.

A grande dificuldade apontada pelo próprio Nalin (2010, p.64) no reconhecimento da nulidade como conseqüência do descumprindo da função social do contrato reside no fato que inexiste nulidade sem previsão legal, sugerindo o doutrinador o reconhecimento de uma nulidade virtual, que de acordo com Marcos Bernardes de Melo (2004, p. 21) "resulta da violação de norma jurídica cogente, proibitiva ou impositiva, que seja silente quanto à sanção da nulidade e que não defina outra espécie de sanção para o caso de ser transgredida"

Bruno Miragem (2012, p. 25) compactua do posicionamento acerca da invalidade jurídica quando da violação da função social do contrato, todavia, acrescenta que além da nulidade da cláusula ou do acordo incidirá o dever de indenizar de quem tenha violado a função social contratual, em face do dano advindo desta.

Esta linha de pensamento se funda no fato de o artigo 927 do Código Civil prever que "aquele que, por ato ilícito (arts. 186 e 187), causar dano a outrem, fica obrigado a repará-1o", assim, pela interpretação do dispositivo tem-se que aquele que descumpre a função social do contrato comete ato ilícito e quando resultar em dano deve ao violador ser imposto o dever de indenizar, podendo a infração da função social do pacto emanar, tanto das partes envolvidas no acordo, tanto dos terceiros alheios ao contrato, nascendo para qualquer um destes o dever de indenizar (LEONARDO, 2005 a p. 70).

A revisão contratual pode ser apontada como o efeito imediato da função socioambiental do contrato, entendimento comungado por Rodrigo Xavier (2005b, p. 57) quando afirma que "o artigo 421 representa um fundamento normativo para o já assentado entendimento de que o princípio da intangibilidade dos contratos cede frente ao poder de revisão e integração das cláusulas contratuais abusivas".

O entendimento mais ponderável quando do descumprimento da função social do contrato parece depender de cada caso concreto.

No campo da existência tem-se que o fato de o contrato estar composto por seus elementos básicos - manifestação de vontade, agente, objeto e forma - não significa que as partes ou terceiros cumprirão com a função social do contrato.

Por evidente que um contrato que descumpre com sua função social, na grande maioria dos casos, cumprirá com seus elementos existenciais 
sendo decorrente de uma manifestação de vontade, emanada por um agente, acerca de um objeto, obedecendo a uma determinada forma, o que não significa que não produzirá efeitos positivos para as partes (efeitos intrínsecos), tampouco para a sociedade (efeitos extrínsecos).

$\mathrm{Na}$ esfera da validade há que se verificar se a manifestação de vontade foi livre e dotada de boa-fé, bem como se o agente emissor da pretensão é capaz e legítimo, se o objeto do contrato é idôneo e se a forma do pacto é prescrita ou não defesa em lei.

$\mathrm{Na}$ grande maioria das vezes tem-se que um pacto que descumpre com a sua função social dificilmente atenderá ao seu plano de validade, haja vista que nestes casos dificilmente o acordo negocial será detentor de um objeto lícito ou não terá a sua forma vedada legalmente.

No plano da eficácia há um processo mais delicado de análise, vez que existente e válido um negócio jurídico, habitualmente passa-se automaticamente à produção de eficácia, entretanto, podem incidir sobre este contrato existente e válido três acidentes que comprometerão a sua eficácia, sendo estes: a) termo - evento futuro e certo, que determina o início e/ou termo final dos efeitos; b) condição - evento futuro e incerto que poderá iniciar a produção dos efeitos ou fazer cessá-los; c) modo ou encargo - determinação acessória acidental dos negócios jurídicos gratuitos, que impõe ao beneficiário da liberdade um ônus a ser adimplido, em prol de uma liberdade maior; o que nem sempre comprometerá a função social do contrato.

Há que se destacar ainda que é sempre prudente uma análise ponderada à possibilidade de conservação do negócio jurídico, que pauta-se no fundamento de que não se deve supor que as partes tenham celebrado um contrato inutilmente e sem seriedade, devendo sempre ser conservado o acordo celebrado quando houver esta possibilidade.

Quando descumprida a função socioambiental do contrato, embora a(s) conseqüência(s) desta inobservância varie de acordo com a análise de cada caso concreto, constata-se que as conseqüências mais ocorrentes são a lesão ao campo de validade do negócio jurídico em conjunto com a aplicação do dever de indenizar, sendo possível ainda se cogitar uma revisão judicial, que pode levar a uma alteração do conteúdo contratual, alterando a obrigação de uma ou de ambas as partes, devolvendo o equilíbrio econômico do pacto. 


\section{CONSIDERAÇÕES FINAIS}

Conclui-se ante os apontamentos apresentados que a economia, o meio ambiente e o direito são indissociáveis, seja pela existência de uma sociedade organizada, seja pela dependência da economia com relação ao meio ambiente, que é regulamentada pelo direito.

Sob este enfoque econômico, verifica-se que para o alcance do desenvolvimento sustentável é imprescindível a aplicação da função social e socioambiental do contrato, que visam garantir tanto às partes celebrantes a satisfação de seus interesses, como resguardar aos terceiros não participantes do pacto que seus direitos não serão lesionados por acordos alheios, devendo os institutos serem invocados quando contratos deixarem de observar sua função social e principalmente sua função socioambiental, colocando em risco o direito difuso de um meio ambiente saudável e equilibrado.

Ante todas as vertentes expostas, quando do descumprimento da função ambiental do contrato a hipótese mais plausível e justa é a de que as conseqüências do descumprimento devem levar em consideração cada caso concreto, optando o magistrado, geralmente pela imposição do dever de indenizar ou pela revisão contratual, considerando sempre a possibilidade de conservação do negócio jurídico, afinal, parte-se da premissa que as partes celebrantes do contrato não o fizeram em vão.

Em suma, para que se consolide a dignidade da pessoa humana, ideários do Estado Democrático de Direito e do Estado Ambiental, não se pode olvidar da indispensabilidade de interação entre o crescimento econômico e o meio ambiente, sendo um dos instrumentos aptos para tanto a função ambiental do contrato, que deverá ser invocada sempre que necessário tanto pelo Estado quanto pela sociedade.

Não se pode olvidar ainda que a consolidação real do Estado Ambiental apenas se dará quando houver a conscientização das presentes e futuras gerações, de que juntos devem conservar os recursos naturais do planeta.

\section{REFERÊNCIAS}

AMARAL, Francisco. O contrato e sua função institucional. Studia Iuridica - Colloquia. Boletim da Faculdade de Direito da Universidade de Coimbra. Coimbra, v. 48, n. 6, 1999/2000, Separata de Conferências. 
BALERA, Wagner. Princípios norteadores do direito previdenciário. Revista de Previdência Social. São Paulo: LTr, n. 82, 1987.

BARBIERI, José Carlos. CAJAZEIRA, Jorge Emanuel Reis.

Responsabilidade social empresarial e empresa sustentável. Da teoria à prática. São Paulo: Saraiva. 2009.

BARROSO, Lucas de Abreu. A função ambiental do contrato. In: DELGADO, Mário Luiz. ALVES, Jones Figueirêdo (organização). Questões controvertidas no novo código civil: no direito das obrigações e dos contratos, v. 4. São Paulo: Método, 2005.

BARROSO, Lucas Abreu. O contrato também possui função ambiental. In: MORRIS, Amanda Zoe (Coordenação); HIRONAKA, Giselda Novaes (Orientação). Direito dos Contratos. São Paulo: Revista dos Tribunais, 2008.

BORGES, Roxana Cardoso Brasileiro. Função ambiental do contrato: proposta de operacionalização de princípio civil para a proteção do meio ambiente. Revista de Direito Ambiental. São Paulo: Revista dos Tribunais, ano 13, n. 49, jan/mar, 2010.

CANOTILHO, José Joaquim Gomes. Estado de Direito. Lisboa: Fundação Mário Soares, 1999.

FACHIN, Zulmar. Curso de direito constitucional. 3 ed. São Paulo: Método. 2008.

GAGLIANO, Pablo Stolze. PAMPLONA FILHO, Rodolfo. Novo curso de direito civil. Contratos: teoria geral. v. IV, tomo $1.7^{\mathrm{a}} \mathrm{ed}$. São Paulo: Saraiva, 2011.

GODOY, Cláudio Luiz Bueno de. Função social do contrato. De acordo com o novo Código Civil. Coleção Agostinho Alvim. São Paulo: Saraiva, 2004. 
GOMES, Sérgio Alves. Hermenêutica constitucional: um contributo à construção do Estado Democrático de Direito. Curitiba: Juruá, 2008.

HABERMAS, Jürgen. Legitimations probleme im Spälkapitalismus. Frankfurt Suhrkamp Erscheinungjahr: 1973.

KLOEPFER, Michael. A caminho do Estado Ambiental? A transformação do sistema político e econômico da República Federal da Alemanha através da proteção ambiental especialmente desde a perspectiva da ciência jurídica. Tradução Carlos Alberto Molinaro. In: SARLET, Ingo Wolfgang (Org.). Estado socioambiental e direitos fundamentais. Porto Alegre: Livraria do Advogado, 2010. p. 43.

KLOEPFER, Michael. Aspekte eines Umweltstaates Deutschland. Eine umweltverfassungsrechtliche Zwischenbilanz. In: DOLDE, Klaus-Peter (Org.). Umweltrecht im Wandel. Bilanz und Perspektiven aus Anlass des 25-jährigen Bestehens der Gesellschaft für Umweltrecht (GfU). Berlim: Erich Schmidt Verlag, 2012.

LEONARDO, Rodrigo Xavier. A função social dos contratos: ponderações após o primeiro biênio de vigência do Código Civil. In: CANEZIN, Claude. Arte Jurídica. V. II. Curitiba: Juruá, 2005.

- A teoria das redes contratuais e a função social dos contratos: reflexões a partir de uma recente decisão do Superior Tribunal de Justiça. In: Revista dos Tribunais, ano 94, vol. 832. São Paulo: Revista dos Tribunais, fev 2005.

MELLO, Marcos Bernardes de. Teoria do fato jurídico: plano da validade. 6 ed. São Paulo: Saraiva, 2004.

MILARÉ, Édis. Direito do ambiente. 7 ed. São Paulo: Revista dos Tribunais, 2013.

MIRAGEM, Bruno. Diretrizes interpretativas da função social do contrato. Revista de Direito do Consumidor, v. 14, n. 56, out/dez, 2012. 
MOLINARO, Carlos Alberto. Racionalidade ecológica e Estado socioambiental e democrático de direito. Dissertação de mestrado. Programa de Pós-graduação em Direito da Faculdade de Direito da Pontifícia Universidade Católica do rio Grande do Sul, 2006.

MORAES, Maria Celina Bodin. In NEGREIROS, Teresa. Teoria do contrato. Novos paradigmas. 2. ed. Rio de Janeiro: Renovar, 2006. Prefácio.

NALIN, Paulo. Do contrato: conceito pós-moderno em busca de sua formulação nas perspectivas civil-constitucional. Curitiba: Juruá, 2010 .

NALINI, José Renato. Ética ambiental. 2 ed. Campinas: Millenium, 2011.

NEGREIROS, Teresa. Teoria do contrato. Novos paradigmas. 2. ed. Rio de Janeiro: Renovar, 2006.

NERY JÚNIOR, Nelson. NERY, Rosa Maria de Andrade. Código civil comentado e legislação extravagante. 2 ed. São Paulo: Revista dos Tribunais, 2003.

NUNES JÚNIOR, Amandino Teixeira. O estado ambiental de direito. Revista de Informação Legislativa. Brasília, n. 163, jul/set, 2010.

POLANYI, Karl. La gran transformación: los orígenes políticos y econômicos de nuestro tiempo. Tradução de Eduardo Suaréz. México: Fondo de Cultura econômica, 1992.

REALE, Miguel. Lições preliminares de direito. 27. ed. São Paulo: Saraiva, 2002.

REICH, Norbert. Mercado y derecho. Tradução de Antoni Font. Barcelona: Ariel, 1985.

SANTOS, Eduardo Sens. O novo código civil e as cláusulas gerias: 
exame da função social do contrato. In: Revista Brasileira de Direito Privado, n. 10. São Paulo: Revista dos Tribunais, abri/jun, 2002.

SOUZA, Paulo Roberto Pereira. A conflituosidade ambiental do desenvolvimento econômico. In: FERREIRA, Jussara Borges Nasser. RIBEIRO, Maria de Fátima (organização). Direito empresarial contemporâneo. São Paulo: Arte \& Ciência, 2011.

Artigo recebido em: 10/04/2014 Aprovado para publicação em: 19/08/2014

Como citar: ARAÚJO, Miguel Etinger Jr. TEIXEIRA, Karina Alves. Função socioambiental do contrato: mecanismo de compatibilidade entre o crescimento econômico e o meio ambiente. Revista do Direito Público. Londrina, v.9, n.2, p.41-62, mai./ago.2014. DOI: 10.5433/1980511X.2014v9n2p41. 